Review

\title{
Relaxor-PT Single Crystal Piezoelectric Sensors
}

\section{Xiaoning Jiang *, Jinwook Kim and Kyugrim Kim}

Department of Mechanical and Aerospace Engineering, North Carolina State University, Raleigh, NC 27695, USA; E-Mails: jkim50@ncsu.edu (J.K.); kkim8@ncsu.edu (K.K.)

* Author to whom correspondence should be addressed; E-Mail: xjiang5@ncsu.edu;

Tel.: +1-919-515-5240; Fax: +1-919-515-7968.

Received: 1 June 2014; in revised form: 8 July 2014 / Accepted: 14 July 2014 /

Published: 28 July 2014

\begin{abstract}
Relaxor- $\mathrm{PbTiO}_{3}$ piezoelectric single crystals have been widely used in a broad range of electromechanical devices, including piezoelectric sensors, actuators, and transducers. This paper reviews the unique properties of these single crystals for piezoelectric sensors. Design, fabrication and characterization of various relaxor-PT single crystal piezoelectric sensors and their applications are presented and compared with their piezoelectric ceramic counterparts. Newly applicable fields and future trends of relaxor-PT sensors are also suggested in this review paper.
\end{abstract}

Keywords: piezoelectric sensors; piezoelectricity; ferroelectrics; relaxor-PT; relaxor-PT single crystals

\section{Introduction}

\subsection{Piezoelectric Sensors}

Electro-mechanical sensors are essential components for various industry and laboratory applications in automotive, aerospace, energy, chemical, biomedical and electronic industries. Currently, electromechanical sensors can be categorized into the following main types based on their sensing principles: piezoresistive, capacitive, piezoelectric, and optic sensing [1,2]. Among these sensors, piezoelectric sensors are known to have features such as fast response, high linearity, high resolution, simple integration, and low cost [3-5]. Piezoelectric sensing can be divided into two main types: resonant and non-resonant (Figure 1). In non-resonant piezoelectric sensing, the direct piezoelectric effect, which is defined as the generation of charge (voltage) by applying a stress, is 
utilized as a sensing mechanism [6]. For non-resonant piezoelectric sensors, the typical operation frequency range is usually much lower than the fundamental resonant frequency of the sensor (e.g., $<30 \%$ of the resonant frequency). This type of sensors usually operates in different sensing modes including compression, shear, and flexural mode. Each mode provides specific benefits in sensitivity, stability, and reliability for specific applications.

Figure 1. Schematic illustration of piezoelectric sensing technology.

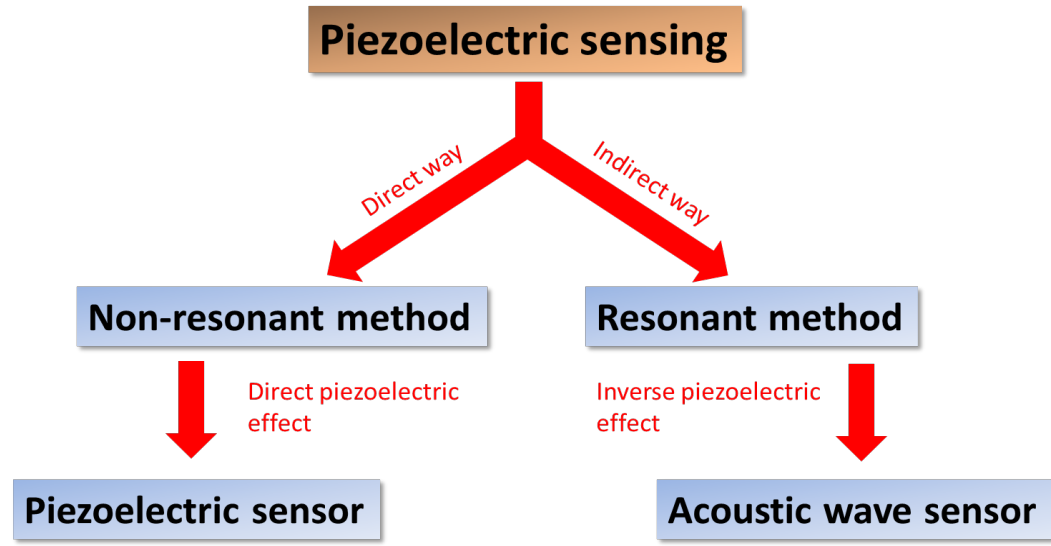

On the other hand, converse piezoelectric effect referred as the generation of strain (stress) upon an applied electric field is also adopted for sensor designs, namely resonant-type sensors or acoustic wave sensors [7]. The resonant piezoelectric sensors are usually designed based on the fact that the pressure amplitude, wave velocity, and center frequency of the generated acoustic waves are dependent on the external stimulus including pressure, temperature, mass loading, etc. In acoustic wave sensors, acoustic waves can be generated at the resonance frequency of the sensor [8], and this is why the acoustic wave sensors are usually called the resonant-type sensors.

Although piezoelectric sensors are known with many favorable features, one limitation of piezoelectric sensors is often mentioned that: non-resonant piezoelectric sensors can only be used for dynamic measurements but not for static measurements. The reason is that non-resonant piezoelectric sensors respond only to a variation of the input load. However, proper circuit design can mitigate this limitation. For example, with a large capacitance, non-resonant piezoelectric sensors can be used for quasi-static measurements [5]. In addition, the resonant piezoelectric sensors exhibit stable performance in static measurements. Therefore, various resonant and non-resonant piezoelectric sensing of vibration, force, flow, pressure, bio, and chemical stimuli have been actively utilized for both dynamic and static measurements in many industrial applications [9-15].

A few review papers on piezoelectric sensors have been published and well received. These papers reviewed piezoelectric sensors based on quartz crystals and lead-based ceramics $[6,16,17]$, and the key features of well-known piezoelectric sensor designs were introduced as well as the associated applications. Typical sensor configurations such as piezoelectric bars, disks, cylinders, spheres, and benders were studied for hydrophones, accelerometers, and bio-sensors [17]. Concerning miniaturization of piezoelectric sensors, Tadigadapa et al. [6] presented a comprehensive review of micro-machined piezoelectric sensor technology with a particular focus on the available micro-fabrication methods. Recently, Jiang et al. [18] reviewed the high temperature piezoelectric sensing technology. In these 
review papers, many piezoelectric materials were investigated, but relaxor-ferroelectric materials were scarcely mentioned in spite of their ultrahigh piezoelectricity. As a future trend of piezoelectric sensors, Tressler et al. [17] briefly mentioned the promising aspects of relaxor ferroelectric single crystals.

\subsection{Relaxor-PT Ferroelectric Crystals}

Among all components of a piezoelectric sensor, properties of the piezoelectric material have the most dominant effect on the sensor performance. Due to the high piezoelectricity, possibility of application-adapted shaping and ease of fabrication, ferroelectric ceramics-based on $\mathrm{Pb}$-containing perovskites have been chosen as active materials for most of the piezoelectric sensors [19-21]. Over the last two decades, relaxor-based ferroelectric single crystals such as $\mathrm{Pb}\left(\mathrm{Mg}_{1 / 3} \mathrm{Nb}_{2 / 3}\right) \mathrm{O}_{3}-\mathrm{PbTiO}_{3}$ ( $\mathrm{PMN}-\mathrm{PT}$ ) and $\mathrm{Pb}\left(\mathrm{Zn}_{1 / 3} \mathrm{Nb}_{2 / 3}\right) \mathrm{O}_{3}-\mathrm{PbTiO}_{3}$ ( $\mathrm{PZN}-\mathrm{PT}$ ) have been spotlighted due to their ultrahigh piezoelectric properties [22,23]. For example, the ultra-high longitudinal piezoelectric strain coefficient $d_{33}(>2000 \mathrm{pC} / \mathrm{N})$ and electromechanical coupling factor $k_{33}(>0.9)$ of the relaxor-PT single crystals far outweigh the mostly used polycrystalline ceramics $\mathrm{Pb}(\mathrm{Zr}, \mathrm{Ti}) \mathrm{O}_{3}(\mathrm{PZT})$, and these merits are promising for a broad range of electromechanical applications [24,25].

The origin of relaxor single crystals' prominence and various compositions, orientations, and crystal growth methodologies were reported by numerous published articles [25-50]. A strong crystal anisotropy in these single crystals were considered as the key factor of their high piezoelectric properties [26,27]. As an example, piezoelectric properties of relaxor-PT single crystals poled along different crystallographic directions can be significantly different, and many of these crystal cut and poling configurations can be unique in many applications [25,28-36]. In the matter of crystal growth methods, various growth techniques including high temperature solution, Bridgman, and solid state conversion methods have been developed and reported [37-40]. Relaxor-PT single crystals with different compositions grown by different growth methods were characterized considering their poling directions and crystal groups. Among many material properties measurement methods, impedance measurement - also called resonant measurement - and the ultrasonic method were commonly used to determine the full matrix of elastic, piezoelectric, and dielectric constants of relaxor-PT crystals [34,41-48]. Material properties of [001] poled relaxor-PT single crystals are compared with those of conventional piezoelectric materials in Table 1 , where $T_{\mathrm{C}}, d, k, \varepsilon^{T}$, and $Q_{\mathrm{M}}$ denote a Curie temperature, a piezoelectric constant, an electro-mechanical coupling coefficient, a dielectric permittivity at constant stress, and a mechanical quality factor, respectively. $\varepsilon_{0}$ is the permittivity of free space, $8.854 \times 10^{-12} \mathrm{~F} / \mathrm{m}$. Based on the published material properties, many papers presented promising applications of relaxor-PT single crystals. For instance, Park et al. [28,49,50] reported the feasibility of the PMN-PT and PZN-PT single crystals for the actuator and transducer applications taking advantage of the ultrahigh piezoelectric coefficients with low hysteresis and large strain behavior of relaxor single crystals. 
Table 1. The material properties of conventional piezoelectric materials and relaxor-PT single crystals [25,51-59].

\begin{tabular}{ccccccccc}
\hline Material & $\boldsymbol{T}_{\mathbf{C}}\left({ }^{\circ} \mathbf{C}\right)$ & $\boldsymbol{d}_{\mathbf{3 1}}(\mathbf{p C} / \mathbf{N})$ & $\boldsymbol{d}_{\mathbf{3} 3}(\mathbf{p C} / \mathbf{N})$ & $\boldsymbol{k}_{\mathbf{3 1}}$ & $\boldsymbol{k}_{\mathbf{3 3}}$ & $\boldsymbol{\varepsilon}_{\mathbf{3 3}}^{\boldsymbol{T}} / \boldsymbol{\varepsilon}_{\mathbf{0}}$ & $\boldsymbol{Q}_{\mathbf{M}}$ & Reference \\
\hline BaTiO $_{3}$ & 115 & -78 & 190 & 0.21 & 0.50 & 1700 & 300 & {$[51]$} \\
PZT-4 & 330 & -123 & 289 & 0.33 & 0.70 & 1300 & 600 & {$[52]$} \\
PZT-5A & 370 & -171 & 374 & 0.34 & 0.71 & 1700 & 75 & {$[52]$} \\
PZT-5H & 195 & -274 & 593 & 0.39 & 0.75 & 3400 & 65 & {$[52]$} \\
PVDF & - & 21 & -32.5 & - & - & 7.6 & 8.5 & {$[53-55]$} \\
PMN-33\%PT & 155 & -1335 & 2820 & 0.59 & 0.96 & 8200 & 100 & {$[25,52]$} \\
PZN-8\%PT & - & -1075 & 2200 & 0.59 & 0.94 & 5100 & - & {$[56]$} \\
PIN-PMN-PT & 197 & -1337 & 2742 & 0.65 & 0.95 & 7244 & 120 & {$[57]$} \\
PMN-PZT & 216 & -718 & 1530 & 0.44 & 0.93 & 4850 & 100 & {$[58]$} \\
Mn:PIN-PMN-PT & 193 & - & 1120 & - & 0.90 & 3700 & 810 & {$[25]$} \\
Mn:PMN-PZT & 203 & -513 & 1140 & 0.45 & 0.92 & 3410 & 1050 & {$[59]$} \\
\hline
\end{tabular}

Recently, Zhang et al. [25] reported in-depth review papers summarizing key features of published works and suggesting a perspective on future development of relaxor-PT crystals. In those articles, crystal growth technique, characterization process, measured results with high piezoelectric properties and low loss characteristics, and performance at a specific application were discussed [25,60,61]. Referring to these papers, the concept of classification of crystals was proposed by Smith [25]. According to this concept, the first generation crystals, e.g., PMN-PT and PZN-PT, show high electromechanical coupling and piezoelectricity which suggests wider bandwidth, higher sensitivity, and higher source level in ultrasonic transducer applications than their conventional PZT ceramic counterparts. The second generation crystals, e.g., PIN-PMN-PT and PMN-PZT, are advanced with a broader operation range of temperature, higher coercive field, and higher mechanical stress limit compared to the first generation crystals. The key feature of the third generation crystals is the greatly increased mechanical quality factor. For example, Mn-doped relaxor-PT crystals, such as Mn:PIN-PMN-PT and Mn:PMN-PZT, exhibit high mechanical quality factor of $\sim 900$, which is about 9 times higher than other generation crystals. However, the third generation crystals are known to have $\sim 20 \%$ decreased piezoelectric and dielectric constants, in comparison with the first and second generation relaxor-PT crystals [25].

As mentioned earlier, well-organized review articles with topics covering material properties of relaxor-PT single crystals and their applications in piezoelectric actuators, transducers, and energy harvesters have been published. However, relaxor-PT crystals as a sensor material have not been extensively reported on so far, largely because these crystals are known to have relatively low transition temperature, coercive field, and mechanical quality factor. As a result, there are a relatively small number of published articles and patents on sensor application of relaxor-PT crystals compared to other applications, such as actuators, transducers, and energy harvesters. Nevertheless, the advancement of relaxor single crystals poses for promising piezoelectric sensing applications.

In this paper, relaxor-PT crystals-based piezoelectric sensors were reviewed. Specifically, relaxor-PT accelerometers, hydrophones, surface load sensors, and bio-chemical sensors were presented with details. These sensors were selected to review because that they showed the most significant 
advancement of sensor performance in comparison with their ceramic counterparts. Analysis of emerging applicable fields and future trends of relaxor-PT sensors were also presented in this review paper.

\section{Relaxor-PT Accelerometers}

In comparison with capacitive and piezoresistive accelerometers, piezoelectric accelerometers exhibit a wide operating frequency range, as well as cost-efficiency, stability, rapid response, ease of integration, and excellent repeatability $[3,62,63]$. Piezoelectric accelerometers are usually non-resonant sensors, with the operation frequency lower than the fundamental resonant frequency. Many piezoelectric materials have been used in accelerometers. Among them, soft PZT ceramics are dominantly used because of their relatively temperature insensitive high piezoelectric and electro-mechanical coupling constants. Despite the more temperature sensitive piezoelectric properties of relaxor-PT single crystals, the much higher piezoelectric constants and lower dielectric loss at low frequency of relaxor-PT single crystals have potentials for the improved performance with low noise and high sensitivity. Thus, several papers on relaxor-PT accelerometers have been reported.

\subsection{Bimorph Accelerometer}

A bimorph type accelerometer composed of PZN-PT and PMN-PT crystals was introduced in 2000 by Wlodkowski et al. [64]. The bimorph design was selected in this accelerometer to take advantage of the high $d_{31}$ of single crystals. The sensitivity of the prototype was measured as $1.5 \mathrm{pC} / \mathrm{g}$. The spectral noise of the prototype with relaxor-PT single crystal was compared with the PZT-based commercial accelerometers. Over a frequency range between 100 and $1000 \mathrm{~Hz}$, the spectral noise of the single crystal-based accelerometer was approximately one order of magnitude lower $(20 \mathrm{~dB})$ than that of its PZT counterparts, and $10 \mathrm{~dB}$ lower at $1 \mathrm{~Hz}$. This is attributed to high $d_{31}$ and low dielectric loss of relaxor-PT single crystals, because the accelerometer noise is inversely proportional to the charge sensitivity, and proportional to the dielectric loss [64].

\subsection{Unimorph Accelerometer}

Wlodkowski et al. [65] also developed a unimorph accelerometer (PUMA) using PZN-PT single crystals. In this work, the merit of relaxor-PT single crystals as sensing materials of piezoelectric accelerometers was highlighted. In addition, a mechanical leverage for amplification of stress input was designed for PUMA (Figure 2). In this flexural mode design, $d_{31}$ of the relaxor-PT crystal dominantly contributes to the improved charge generation, and the small compression of the sensing material along the acceleration direction also affects the output charge. Thus, PZN-PT PUMA was expected to exhibit improved sensitivity because of its five times higher $d_{31}$ and $d_{33}$ than soft PZT ceramics. The FEA results showed that sensitivity improvement by the sensing material substitution from PZT to PZN-PT is much higher than that by design changes. The final PUMA prototype made of PZN-PT showed a charge sensitivity of $75 \mathrm{pC} / \mathrm{g}$ and a resonance frequency of $19.4 \mathrm{kHz}$ [65]. This work demonstrated that the first generation relaxor-PT crystals can be integrated into the novel accelerometer design for significantly improved signal-to-noise ratio (greater than $15 \mathrm{~dB}$ ) by taking advantages of their high $d_{33}$ and $d_{31}$ [64]. 
The piezoelectric accelerometers comprised of PZN-PT single crystals were also commercialized by Microfine Materials Technologies in Singapore. The reported sensitivity is $25,000 \mathrm{pC} / \mathrm{g}$ or $2.5 \mathrm{~V} / \mathrm{g}$, which is about a thousand times higher than that of conventional PZT-based accelerometers, and the dynamic range is from $10 \times 10^{-6} \mathrm{~g}$ to $20 \mathrm{~g}[25,66]$.

Figure 2. PUMA operating in the flexural mode. Reprinted with permission from [65]. Copyright 2001 Elsevier.

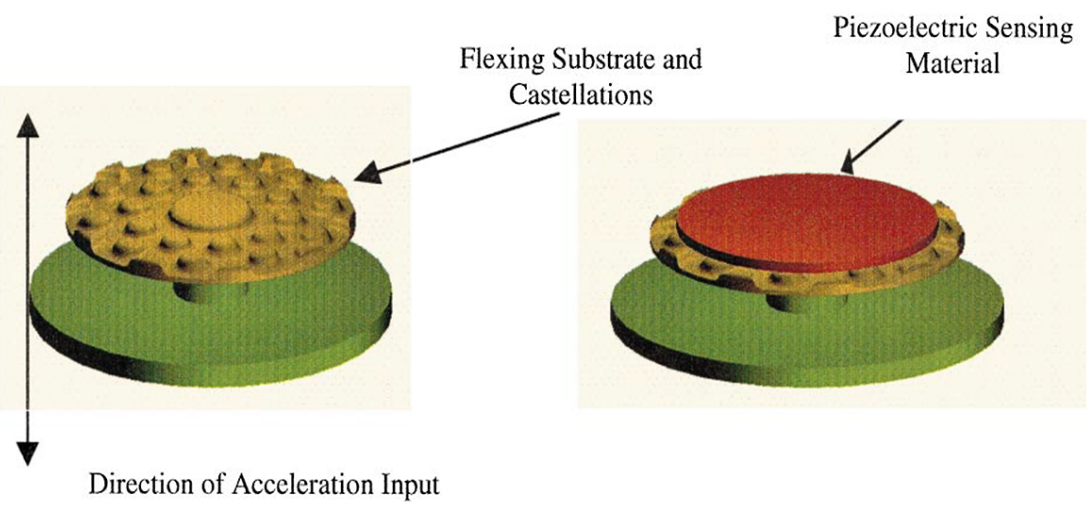

\subsection{PIN-PMN-PT for Shear Mode Accelerometer Application}

It was suggested that high piezoelectric and electromechanical coupling constants of the relaxor-PT crystal may contribute to the increased sensitivity of accelerometers. However, the first generation crystals cannot be used over a large range of stress, electric field, and temperature [67-70]. Thus, PIN-PMN-PT, the second generation crystal, was considered as a sensing material. The rombohedral phase over a broader temperature can be stabilized by compositional modification and addition of dopants. As a result, the temperature and electric/stress field which may induce phase transition of crystals increase, and hence more stable crystal properties can be obtained over a broad range of temperature and electric field [71]. Goljahi et al. [72] reported a simple method to identify crystal cuts of PIN-PMN-PT crystals with desired properties for accelerometers. Specifically, crystal cuts for large $d_{312}\left(=d_{36}\right)$ and zero $d_{311}\left(=d_{31}\right)$ or equivalently large $d_{36}$ and zero $d_{32}$ can be useful for a highly sensitive shear mode accelerometer design. Based on the theoretical analysis, specimens were cut in the orientation that gives a large $d_{36}$ and zero $d_{32}$. The measured strains induced by applying electric field were used to calculate piezoelectric constants, and then compared with theoretical values. As a result, it was demonstrated that PIN-PMN-PT single crystals have the optimal crystal cut ( $52^{\circ}$ rotated) for minimum mode coupling. Thus, this idea can be utilized for the high signal-to-noise ratio of shear mode accelerometers by minimizing noises induced by other vibration modes.

\subsection{Summary}

Table 2 summarizes the specifications of published relaxor-PT accelerometers and conventional PZT accelerometers for comparison. In summary, relaxor-PT crystal accelerometers feature high sensitivity due to their high piezoelectric properties. In particular, the commercialized PZN-PT single crystal accelerometer shows an outstanding sensitivity compared to accelerometers made by PZT. In addition, the optimal crystal cut may lead to novel shear mode relaxor-PT crystal accelerometers. 
Table 2. Comparison between published relaxor-PT accelerometers and PZT accelerometers [64-66,73].

\begin{tabular}{cccccc}
\hline Material & Mode & $\begin{array}{c}\text { Dimension } \\
\left(\mathbf{m m}^{\mathbf{3}}\right)\end{array}$ & $\begin{array}{c}\text { Sensitivity } \\
(\mathbf{p C} / \mathbf{g})\end{array}$ & $\begin{array}{c}\text { Frequency } \\
\text { range }(\mathbf{H z})\end{array}$ & Reference \\
\hline PZN-PT & $\begin{array}{c}31 \text { mode } \\
\text { (flexural unimorph) }\end{array}$ & $\sim(6)^{2} \pi \times 2$ & 75 & $110 *$ & {$[65]$} \\
PZN-PT & - & $\sim(18)^{2} \pi \times 29$ & 25,000 & $0.1-200$ & {$[66]$} \\
PZT & $\begin{array}{c}31 \text { mode } \\
\text { (flexural unimorph) }\end{array}$ & $\sim(6)^{2} \pi \times 2$ & 26 & $110 *$ & {$[65]$} \\
PZT thick film & 31 mode & $6 \times 6 \times 0.01$ & 7.6 & $44-3,700$ & {$[73]$} \\
\hline * The sensitivity was measured at this frequency which is much lower than the resonant frequency (19.4 kHz) [65], \\
but the operation frequency range was not mentioned in this paper.
\end{tabular}

\section{Relaxor-PT Hydrophones}

\subsection{Hydrophone Materials}

Hydrophones are usually used to detect the pressure variations in water. For underwater detection, the towed array sonar system (TASS) composed of small piezoelectric hydrophones in linear arrangement have become popular [74]. Although the development of fast and versatile signal processing algorithms is important to improve the performance of hydrophone systems, stable pressure sensing with high sensitivity by hydrophone elements is the most important factor for underwater applications [75]. Thus, hydrophones are required to have high, stable, and flat sensitivity over a wide band below the resonance. Another important point of the hydrophone is a sea noise level because the limit of detection (LOD) depends on this noise level if the internal hydrophone noise plus the preamplifier input noise is lower than the sea noise [52].

For these concerns of hydrophones, a couple of required properties of the piezoelectric materials can be summarized. First, it is obvious that high piezoelectric constants are required for the high sensitivity. Second, high dielectric constants enable easier electrical matching with low electrical impedance. Third, low dielectric loss is necessary for the low noise generation [52]. Fourth, excellent piezoelectricity at hydrostatic condition should be considered for the underwater applications. The receiving sensitivity of a piezoceramic plate or disk is proportional to its hydrostatic charge coefficient $d_{\mathrm{h}}$, which is equal to the response from the thickness mode, $d_{33}$, plus its response from the planar or lateral mode, $d_{31}+d_{32}=2 d_{31}$, described as $d_{\mathrm{h}}=2 d_{31}+d_{33}$ [76,77]. Lastly, less temperature dependence of piezoelectric and dielectric properties is required for the stable performance of hydrophones.

PZT-5A has been widely used as a sensing material for hydrophones. In addition, piezoelectric polymers such as polyvinylidene fluoride (PVDF) and vinylidene fluoride-trifluoroethylene copolymer $[\mathrm{P}(\mathrm{VDF}-\mathrm{TrFE})]$ have been used as an active element in hydrophones due to their high piezoelectric voltage constant $g$ [78-80]. However, their actual sensitivities were not high enough, and the low dielectric constants of piezoelectric polymer hydrophones were not desirable since the output signals of the sensing elements greatly diminish due to the capacitance of the coaxial cables [81]. 


\subsection{Needle Hydrophone}

Lau et al. [81,82] used PMN-PT single crystals as the sensing elements to fabricate needle-type hydrophones operating in the megahertz frequency range. In this work, PMN-PT single crystal with $65 \mathrm{~mol} \%$ of PMN grown by a modified Bridgman method was used [83]. The fabricated hydrophone exhibited resonant frequency of $4 \mathrm{MHz}$. In contrast to the conventional hydrophones that operate at the frequency range much lower than the fundamental resonance, this relaxor-PT hydrophone showed promising sensitivity at a wide frequency range from below the fundamental resonance to the next harmonic resonance. It was suggested that high piezoelectric constants and high permittivities are critical factors alleviating the cable shunting problem. The sensitivity of the needle hydrophone was measured and compared to the commercial PVDF hydrophone. With a $\sim 0.22 \mathrm{~mm}^{2}$ sensing area, PMN-PT needle hydrophone showed the end-of-cable loaded sensitivity of $0.05 \mu \mathrm{V} / \mathrm{Pa}$ at $20 \mathrm{MHz}$ whereas the PVDF membrane showed that of $0.03 \mu \mathrm{V} / \mathrm{Pa}$ at $20 \mathrm{MHz}$ [81].

\subsection{Cymbal Hydrophone}

Although PMN-33\%PT materials are known with high $d_{31}$ and $d_{33}$, the signs of these are opposite. This counteraction effect actually reduces $d_{\mathrm{h}}$ values. Thus, the advantages of relaxor-PT crystals cannot be sufficiently utilized. Therefore, relaxor-PT single crystal piezoelectric composites may be considered due to their high hydrostatic characteristics. In general, piezoelectric composites are known to have low acoustic impedance, high electromechanical coupling factor, and mechanical flexibility, and hence are attractive to hydrophone applications. In addition to conventional composite structures, such as 1-3, 2-2, and 0-3 composites with relaxor-PT as an active material [84,85], the special composite structures including cymbal transducer can also be designed for better usage of high piezoelectricity of relaxor-PT single crystals. The cymbal transducer was originally developed by Newnham et al. [86-88] in 1990s. This cymbal structure converts the radial motion of the piezoelectric ceramic into a flextensional motion in the metal endcaps, resulting in a large displacement at the center of the endcaps. This mechanism was investigated with a PMN-33\%PT plate integrated into a cymbal hydrophone [89]. Schematic structure of the cymbal transducer is shown in Figure 3a. The receiving voltage sensitivity (RVS) was calculated by finite element analysis (FEA). The RVS spectrum of PMN-PT cymbal was compared with that of PZT-5A cymbal with same structural parameters such as the height of the cavity and the thickness of the brass cap. In addition, the cymbal's structural parameters are changed independently to determine the optimal design for high sensitivity. Two cymbal hydrophones with the PMN-PT crystal and the PZT-5A ceramic were fabricated. The PMN-PT cymbal hydrophone showed about 4 dB higher sensitivity than PZT-5A hydrophone (Figure 3b) [89].

The second generation relaxor-PT crystal hydrophones were reported by Gao et al. [90]. The hydrostatic pressure-dependent properties of PMN-32\%PT and PIN-PMN-PT single crystals were investigated in this work. As a result, the remnant polarization of PZT-5 ceramics could not fully recover after the applied pressure was removed, while there was no pressure-induced depolarization for the second generation relaxor-PT crystals in the pressure range of $0 \sim 530 \mathrm{MPa}$. Moreover, the hydrostatic piezoelectric coefficient $d_{\mathrm{h}}$ for these relaxor-PT single crystals was nearly independent of loaded pressure. This study revealed that the second generation relaxor-PT single crystals have more suitable 
material properties for the design of underwater hydrophone compared with counterpart ceramics and the first generation crystals [91].

Figure 3. (a) The structure of a cymbal transducer; (b) Measurement voltage sensitivity of PZT and PMN-PT hydrophones. Reprinted with permission from [89]. Copyright 2012 Elsevier.

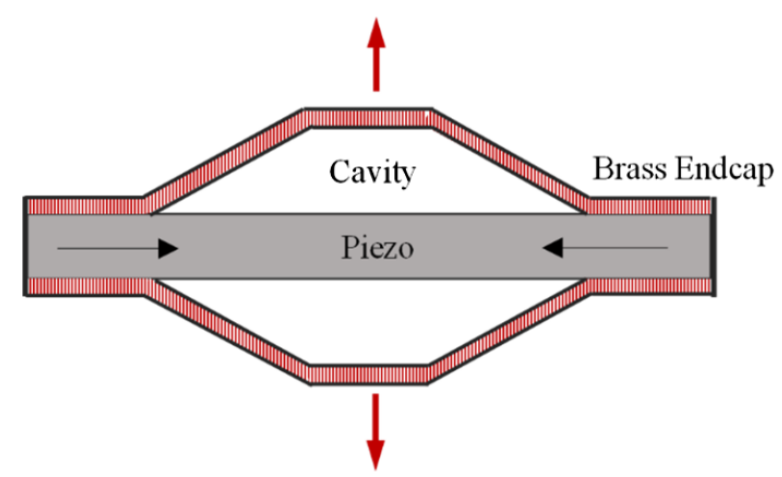

(a)

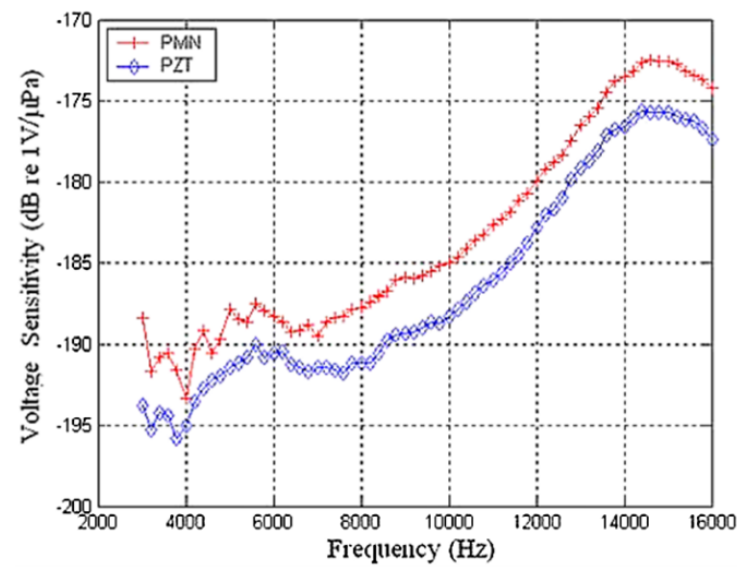

(b)

\subsection{Cylinder Hydrophone}

Recently, Brown et al. [74] developed a cylinder-shaped composite hydrophone that operates in radial vibration mode. Instead of a conventional single ring structure, multiple long strip crystal elements were configured to encircle a cylinder (Figure $4 \mathrm{~b}$ ). With this design, each element maintains the optimal crystal axis for 31 mode around the hydrophone circumference. This 31 mode piezoelectric cylinder hydrophone was designed with $<110>$ cut PMN-PT single crystals (TRS Technologies, State College, PA, USA) due to its high piezoelectric voltage constants $g_{31}$ and $g_{32}$. The schematic illustration of fabrication process is shown in Figure 4a.

Figure 4. (a) Diagram of composite piezoelectric cylinder fabrication process; (b) Photograph of the PMN-PT composite hydrophone (left) and PZT-5A solid hydrophone (right). Reprinted with permission from [74]. copyright 2013 Acoustical Society of America.

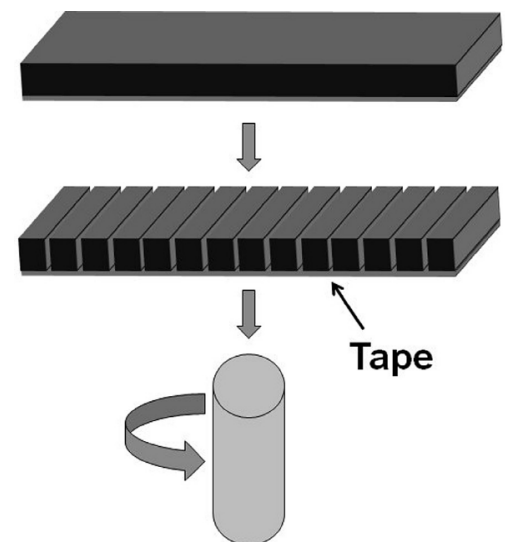

(a)

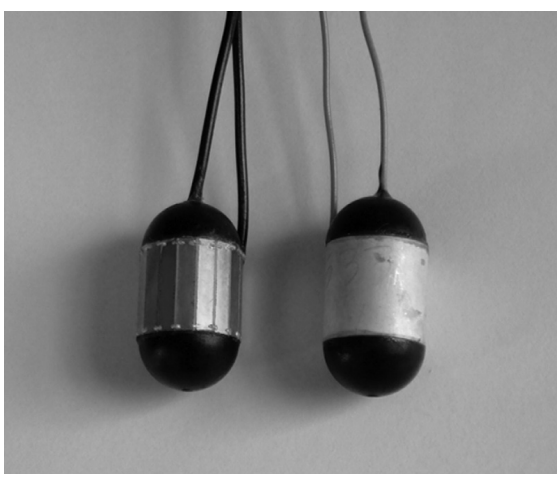

(b) 
The fabricated hydrophone was characterized and compared with the prototype composed of PZT-5A. The relative improvement in charge sensitivity, voltage sensitivity, and figure of merit (FOM) of the PMN-PT based hydrophone was $\sim 9.1 \mathrm{~dB}, \sim 3.5 \mathrm{~dB}$, and $6.3 \mathrm{~dB}$ higher than those of the PZT-5A hydrophone, respectively. The size of the PMN-PT hydrophone can be reduced by half of the PZT-5A hydrophone due to its high sensitivity [74]. This result showed a promising point that a certain combination between various crystal cut orientation and suitable design for the sensing mode can improve the performance or reduce the size of hydrophones.

\subsection{Vector Hydrophone}

By using relaxor-PT single crystals, the size of vector hydrophones could be reduced. The vector hydrophone is an acoustic sensor which is sensitive to both magnitude and the direction of the pressure wave. This is also called a vector sensor, differentiating it from typical scalar sensors. The main advantage is the ability to yield directional information from simple single or dual element hydrophone designs [52]. The basic structure of the vector sensor is comprised of tri-axial accelerometers (Figure 5) [92]. As aforementioned in this chapter, TASS have been of great concern, so the vector hydrophones were intended to be used in this towed array application. However, in the past, vector hydrophone using conventional PZT ceramics for TASS could not meet the Navy's requirements due to limitations in the sensor's signal-to-noise ratio, large size, and associated issues with neutral buoyancy [93]. Thus, Clay et al. [93,94] studied the PMN-PT crystal vector hydrophones and realized the miniaturized vector hydrophones satisfied Navy requirements, such as the frequency range of $3 \mathrm{~Hz}$ to $7 \mathrm{kHz}$, the sensitivity of $-174 \mathrm{~dB}$ re $\mathrm{V} / \mu \mathrm{Pa}$, and operating temperature range of -40 to $60{ }^{\circ} \mathrm{C}$ within the dimension of $71.3 \mathrm{~mm}$ in length and $40.7 \mathrm{~mm}$ in diameter. In their design, the PZT ring hydrophone for omnidirectional sensing was combined with three PMN-PT accelerometers along $x, y$, and $z$ directions for pressure sensing. Due to the high piezoelectricity of the PMN-PT crystals in accelerometers, the dipole and cardioid directivity patterns exhibit $4.8 \mathrm{~dB}$ improvement in the signal-to-noise ratio over the omnidirectional hydrophone.

Figure 5. Conventional design of the vector hydrophone.

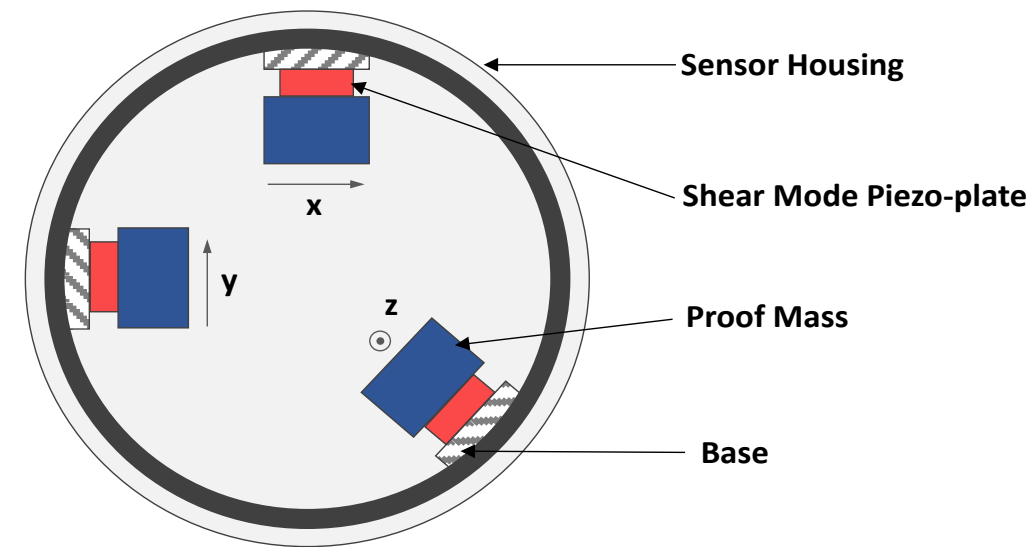

The shear mode accelerometers were also investigated as tri-axial accelerometers [95] in a vector hydrophone design. [111] poled PMN-PT crystals were used in accelerometers due to their large sensitivity difference between the sensing direction and other directions. The $d_{31}$ and $d_{33}$ is $-900 \mathrm{pC} / \mathrm{N}$ 
and $2000 \mathrm{pC} / \mathrm{N}$, respectively, whereas the $d_{15}$ is about $4600 \mathrm{pC} / \mathrm{N}$ [25]. Thus, these accelerometers have affordable sensitivity along the sensing direction with the minimum spurious sensitivity to other directions.

\subsection{Summary}

The specifications of published relaxor-PT hydrophones compared to conventional PZT hydrophones are summarized in Table 3. In summary, the sensitivity of relaxor-PT crystal hydrophones exhibit approximately $4 \mathrm{~dB}$ increased sensitivity than conventional hydrophones in the similar sizes. Hydrophone sizes can be reduced if relaxor-PT crystals are adopted.

Table 3. Key features of published relaxor-PT hydrophones compared to PZT hydrophone $[74,81,89]$.

\begin{tabular}{|c|c|c|c|c|c|}
\hline $\begin{array}{c}\text { Piezoelectric } \\
\text { Material } \\
\end{array}$ & Mode & Dimension & $\begin{array}{c}\text { Sensitivity } \\
\text { (dB re } 1 \mathrm{~V} / \mu \mathrm{Pa})\end{array}$ & $\begin{array}{c}\text { Frequency } \\
\text { Range (kHz) }\end{array}$ & Reference \\
\hline PMN-PT & $\begin{array}{c}33 \text { mode } \\
\text { (harmonic) }\end{array}$ & $0.23\left(\mathrm{~mm}^{2}\right) \times 0.25(\mathrm{~mm})$ & $-266.2 *$ & $17,000-24,000$ & [81] \\
\hline PMN-PT & 31 mode & $10^{2} \pi\left(\mathrm{mm}^{2}\right) \times \sim 3(\mathrm{~mm})$ & $\geq 190^{\#}$ & $<8$ & [89] \\
\hline PMN-PT & 31 mode & $(5.65)^{2} \pi\left(\mathrm{mm}^{2}\right)$ & -197 & $1-8$ & {$[74]$} \\
\hline PVDF & - & $0.23\left(\mathrm{~mm}^{2}\right) \times 0.025(\mathrm{~mm})$ & $-270.2 *$ & $17,000-24,000$ & [81] \\
\hline PZT-5A & 31 mode & $10^{2} \pi\left(\mathrm{mm}^{2}\right) \times \sim 3(\mathrm{~mm})$ & $\leq 194^{\#}$ & $<8$ & [89] \\
\hline PZT-5A & 31 mode & $(5.65)^{2} \pi\left(\mathrm{mm}^{2}\right)$ & -201 & $1-8$ & [74] \\
\hline
\end{tabular}

\section{Relaxor-PT Surface Load Sensors}

Surface load sensors, or tactile sensors, are usually used to sense the surface touch. Conventional piezoelectric tactile sensors are based on the direct piezoelectric effect or measuring variations of the resonant frequency caused by interaction between piezoelectric resonators and target materials $[4,96]$. In the medical field, piezoelectric tactile sensors made by conventional PZT ceramics and commercial piezoelectric sensors have been developed for measuring the elastic stiffness of tissues [97-99]. Another piezoelectric tactile sensing technique utilizes the relationship between the electrical impedance of the piezoelectric resonators and the front acoustic load, which has been demonstrated for fingerprinting applications [100,101]. The mapping of the acoustic load distribution can then be obtained by measuring the electrical impedance of each element of an array [4]. For this sensing technique, the higher acoustic load sensitivity of piezoelectric elements is required to obtain sensing with the high signal-to-noise ratio.

\subsection{Face Shear Mode Sensor}

Kim et al. [102] suggested a new type of surface load sensor using PMN-PT and PIN-PMN-PT single crystals. The most significant feature of this work is that the face-shear mode resonator was used for measurements of surface load-induced electrical impedance magnitude change of the resonator. The face-shear mode was considered a promising vibration mode for this type of sensor since relaxor-PT crystals have a high piezoelectric coefficient, $d_{36}$, in the range of 1600-2800 pC/N; ultrahigh elastic 
compliances accompanying ultralow frequency constant, $N_{36}$, in the range of $490-640 \mathrm{~Hz} \cdot \mathrm{m}$; and significantly higher mechanical quality factor $Q_{\mathrm{M}}(150$ to 180$)$ than that of thickness-shear crystals (20 to 30). The merit of the low frequency constant is that the sensor can be easily miniaturized for ultra-low-frequency applications such as sonar transducers. In addition, unlike the thickness-shear-mode crystals, the use of the same electrode for both poling and sensing is one advantage of the face-shear-mode crystals because crystals can be easily repolarized [103,104].

In Kim's work, electrical impedance changes at the resonant and anti-resonant frequencies in relation to different surface loads were estimated using a KLM model. Three different modes were considered in modeling and experiment process: thickness mode (or $d_{33}$ mode) of PMN-PT, thickness-shear mode (or $d_{15}$ mode) of PMN-PT and face-shear mode (or $d_{36}$ mode) of PIN-PMN-PT [4,102]. The KLM modeling results for sensitivity of each resonator under different surface loadings were compared. The face-shear-mode sensor showed the highest sensitivity of $63 \Omega /$ Mrayl at the resonant frequency, which was 55 times higher than other modes. This is attributed to the fact that the face-shear-mode has higher mechanical quality factor than other modes, which determines the quality of resonance and the sensitivity to the load [4]. In the experiment, the liquid silicone rubber (about $2 \mathrm{~mm}$ thick) with and without $\mathrm{Al}_{2} \mathrm{O}_{3}$ powders $(10 \%, 20 \%, 30 \%$, and $40 \%$ of the silicone rubber by weight) was applied to one large surface of the crystal resonators. The acoustic impedance and velocity of the sensing layer increased with the composition ratio of aluminum oxide powders. The electrical impedance spectrum of each resonator was measured using an Agilent 4294A precision impedance analyzer (Agilent Technologies Inc., Santa Clara, CA, USA). The experiment result showed that the electrical impedance of the face-shear mode resonator at the resonant frequency and anti-resonant frequency increase and decrease rapidly with the increasing acoustic impedances of surface loads, as shown in Figure 6.

Figure 6. Comparison of measured electrical impedance and sensitivity $\left(S_{z}\right)$ under different surface loads for face-shear mode (FS), thickness-shear mode (TS), and thickness mode (T) resonators. (a) Measured electrical impedance at the resonant frequency; (b) Measured electrical impedance at the anti-resonant frequency. Reprinted with permission [102]. Copyright 2012 Elsevier.

(a)

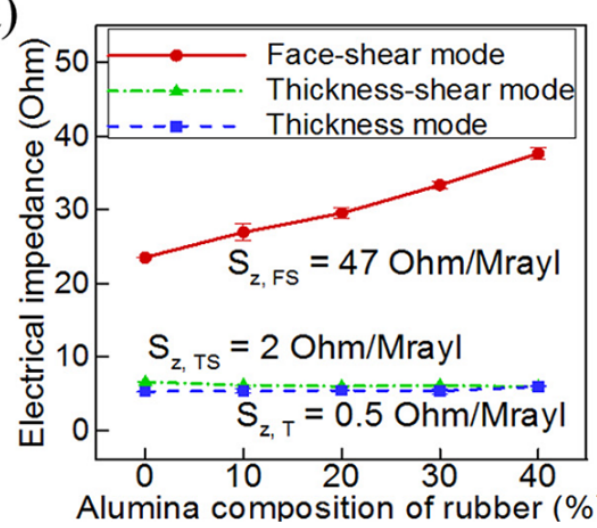

(b)

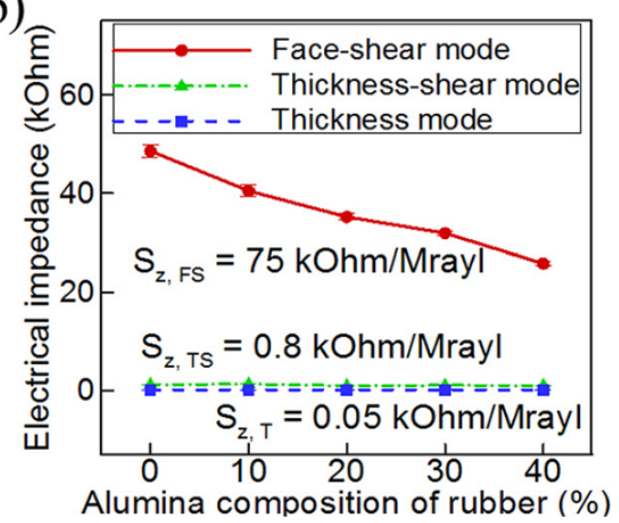


The measured sensitivities were slightly lower than the calculated values, which was attributed to the additional resistance in wire and silver-epoxy at the measurement. Therefore, the feasibility of the relaxor-PT acoustic load sensor was confirmed by this work revealing that more energy dissipation occurs in face shear resonators under surface loads [102], which is promising for tactile sensing applications.

\subsection{Tactile Sensor Array}

A face-shear-mode tactile sensor array was next developed upon the demonstration of the face-shear-mode acoustic load sensor [105]. The tactile sensor array is composed of $64(8 \times 8)$ sensing elements. Each sensing element is the face-shear-mode acoustic load sensor which consists of PMN-PT single crystal and the polymer layer. In this work, polydimethylsiloxane (PDMS) was used as the sensing layer since it is transparent, flexible and has low acoustic impedance. The dimension of each sensing element is $820 \mu \mathrm{m} \times 820 \mu \mathrm{m} \times 300 \mu \mathrm{m}$, and the spatial resolution of the array is approximately $1.1 \mathrm{~mm}$. The fabricated sensor array was characterized and tested. Water and isopropylalcohol (IPA) drop was applied to the top surface of the array for the acoustic load test and the object imaging test (Figure 7a). The electric impedance shift of 64 elements at resonant and anti-resonant frequency results from applied liquid drop was measured. The mapped image of water droplet shape is shown in Figure $7 \mathrm{~b}$. The dark elements in the mapped image show lager electric impedance shift whereas the bright area indicated small impedance shift at the resonant frequency. The surface force distribution on the sensing array and the droplet thickness change affected the variation of electrical impedance shift [105].

Figure 7. (a) Sensor array with an applied water drop; (b) Mapped image for water drop. Reprinted with permission from [105]. Copyright 2013 IEEE.



(a)

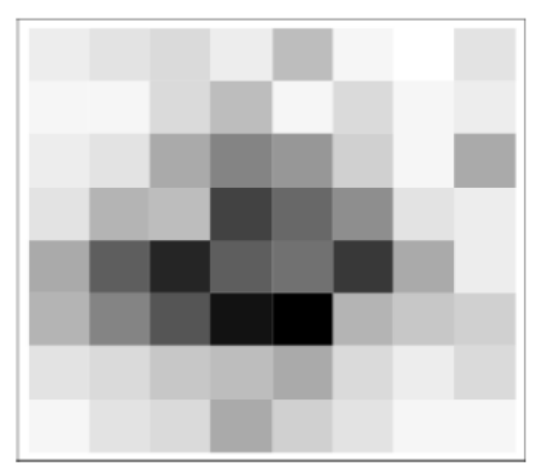

(b)

\section{Relaxor-PT Bio-Chemical Sensors}

\subsection{Conventional Sensors}

Highly sensitive and miniaturized bio-chemical sensors have been in great demand for detection of chemical agents, biomarkers, and biological pathogens [106,107]. Many sensors can be used to detect surface mass changes resulted from the incorporation of biological and chemical molecules on a sensitive surface area. Although the optical systems have been presented as the most advanced sensor system, piezoelectric devices represent a similar but significantly less expensive alternative [108-110]. 
In general, piezoelectric resonant sensors, or acoustic wave sensors, are sensitive to changes in mass induced by the bio-recognition reaction. According to the Sauerbrey equation, piezoelectric sensors with high resonant frequency can usually exhibit high sensitivity [111]. In addition, piezoelectric materials with high mechanical quality factor are usually used for acoustic bio-sensors. For example, the quartz crystal microbalance (QCM) has been used to measure very small mass changes in the order of pictograms (Figure 8) [5,112]. To detect the presence of pathogens in aqueous samples, QCM with immobilized antibody to pathogens have been successfully utilized [113]. Recently, the T-shaped piezoelectric zinc oxide $(\mathrm{ZnO})$ microcantilever was developed for bio-chemical sensing [114]. The T-shaped design showed much higher sensitivity at the resonant frequency than the normal rectangular design.

Figure 8. The conventional quartz crystal micro balance design. Reprinted with permission from [112]. Copyright 2011 Elsevier.
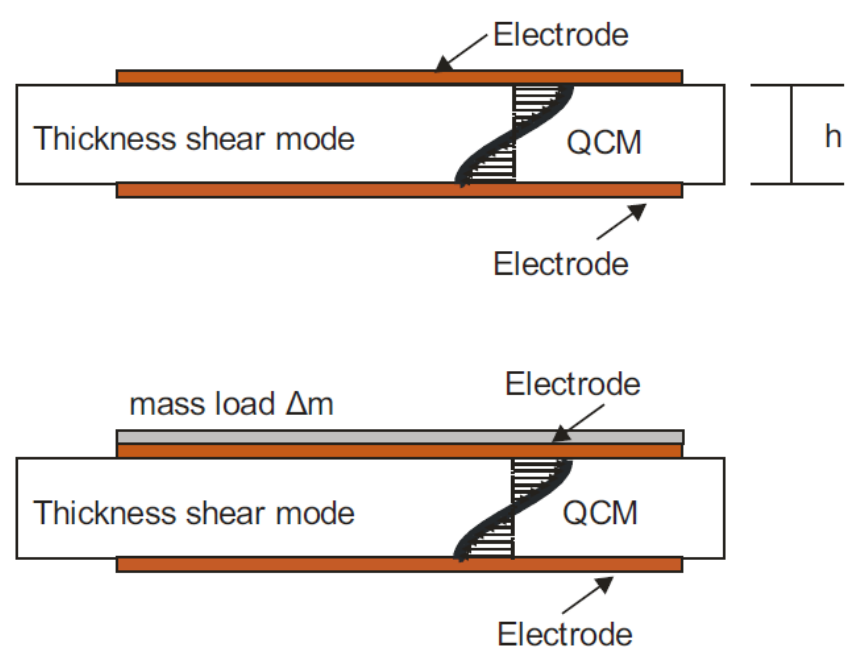

\subsection{Relaxor Single Crystal Micro-Balance}

If the quality factor is the only influential parameter for the high sensitivity of the resonant type sensor, the relaxor ferroelectrics $(\sim 100)$ cannot be compared to the quartz $(\sim 27,000)$ as a sensing material [6]. However, the ultrahigh electromechanical coupling of relaxor crystals has a great potential to increase the sensitivity of resonant type mass detection sensors [115]. The frequency shift $(\Delta f)$ of the relaxor crystals is caused by the thickness change $(\Delta t)$. The strain $(\Delta t) / t$ resulting from the applied mass can induce the frequency shift by the formula of $(\Delta f) / f_{\mathrm{r}}=(\Delta t) / t$, where $f_{\mathrm{r}}$ and $t$ are the resonant frequency and the initial thickness, respectively. The large strain accordingly induces large frequency shift of thickness-extensional or thickness-shear mode sensors [116]. Thus, an initial test using relaxor-PT single crystals as sensing materials was conducted by Hong et al. [117] and the performance was compared with the commercial QCM. Sensing mechanism was similar to the QCM, but the large strain level (1.2\%) of PMN-PT and PZN-PT single crystals was utilized. Those crystals were used to fabricate various bio-sensors with different sizes and frequencies. One noticeable point in this work is that ultrathin single crystal films $(7 \mu \mathrm{m})$ were fabricated using the crystal ion slicing (CIS) technique. The sensitivity test results showed that the percent change of resonant frequency of the PMN-PT small sensor is $0.6 \%$. This indicates 1000 times more frequency drop for the same 
environmental conditions of water condensation as the quartz. In addition, the PZN-PT film bio-sensor showed the smooth transient response with the percent change of $1.4 \%$. Therefore, this work confirmed that proposed bio-chemical sensors composed of relaxor-PT single crystals have the superior sensitivity over conventional QCM due to the high piezoelectricity of single crystals [117].

\subsection{SAW Sensor}

Moon et al. [118] demonstrated relaxor-PT surface acoustic wave (SAW) bio-chemical sensors. The inter-digital electrode configuration with the periodic $100 \mu \mathrm{m}$ spacing was applied on a $10 \mathrm{~mm}$ long PMN-PT cantilever with the resonant frequency of $7.5 \mathrm{MHz}$. The chemical vapor load sensitivity of a prototype sensor was tested in a chamber filled with the methanol vapor, where the sensor was connected to an oscillator and a frequency counter. As a result, the PMN-PT SAW resonator sensor showed a frequency shift of $\sim 40 \mathrm{kHz}$, which is about 300 times higher than QCM $(\sim 120 \mathrm{~Hz})$. One important point in this work is that high temperature sensitivity of the first generation relaxor-PT single crystals was considered as a challenge for a bio-chemical sensor application. It was observed that the relaxor-PT sensor exhibited much bigger resonance frequency change only with temperature variation in the absence of the vapor loading than QCM. This is due to the temperature dependence of piezoelectric and dielectric constants of PMN-PT single crystals. For example, [001] poled PMN-PT crystal shows about 100 percent increased $d_{33}$ at $70{ }^{\circ} \mathrm{C}$ in comparison with the value at room temperature $\left(25^{\circ} \mathrm{C}\right)[25]$.

\subsection{PMN-PT Micro-Cantilever Sensor}

McGovern et al. [119] initially reported in situ detection of Bacullus anthracis (BA) spores using the PMN-PT crystal as a sensing material. They developed PMN-PT/Sn piezoelectric micro-cantilever sensors (PEMS) which were electrically insulated with methyl-trimethoxysilane (MTMS) coatings on the tin surface. Although the direct comparison between conventional PZT ceramic cantilever sensors and relaxor-PT PEMS was not mentioned in this paper, the advantages of their design using PMN-PT crystals were presented. This finding indicated that PMN-PT PEMS can withstand liquid damping better and exhibit a much larger $Q$ factor in liquid, despite of their low $Q$ factor in air $(\sim 75)$. As a result, the PEMS $\left(500 \times 800 \times 42 \mu^{3}\right)$ exhibited the resonant frequency shift of $2100 \pm 200 \mathrm{~Hz}$ at concentration of 20,000 spores/mL [119].

\subsection{PMMA-PMN-PT Sensor}

Recently, Frank et al. [120] reported more increased sensitivity of PMN-PT bio-chemical sensors using a polymethylmethacrylate (PMMA) film. They demonstrated that PMMA coating on a PMN-PT single crystal resonator is useful for detecting chemical agents such as acetone, methanol, and isopropyl alcohol (IPA) vapors. PMMA was used as a chemical adsorption layer. When the chemical vapors are adsorbed to this layer, the PMN-PT thickness shear mode (TSM) crystal can sense larger mass and strain change. The fabricated sensor prototypes were tested with different chemical agents, and the frequency shift was compared with the conventional QCM sensor combined with PMMA sensing layer. The experiment results showed that PMMA coated PMN-PT exhibited sensitivity more 
than 6800 times higher to IPA, acetone, and methanol vapors than that of the PMMA coated QCM [120]. However, the high temperature sensitivity and poor stability of the PMN-PT sensors compared to the QCM sensors were mentioned as problems to solve.

\section{Summary and Future Perspectives}

\subsection{Summary}

Since the 1990s, relaxor-PT single crystals have been utilized for piezoelectric accelerometers, hydrophones, acoustic load sensors and bio-chemical sensors. The number of published journal papers and patents about relaxor-PT crystals for sensor applications are not as many as for actuators or transducers. However, the prominence of the high piezoelectricity of relaxor-PT crystals was sufficiently highlighted in the published results. In summary, relaxor-PT single crystal piezoelectric sensors have been demonstrated to feature the following promising observations:

(a) High sensitivity can be achieved due to their incomparably high piezoelectric constants;

(b) Due to their high dielectric constants, electrical matching with associated electrical systems and a quasi-static measurement by direct piezoelectric effect becomes more practical;

(c) Sensors operating as a non-resonant type can exhibit low noise level at low frequency range due to their low loss tangent;

(d) The optimal piezoelectric property for the designated sensing mode (thickness mode, lateral extension mode, thickness shear mode, and face shear mode) can be achieved by engineering the crystal cut and poling directions;

(e) As a fabrication or a maintenance procedure of thickness mode, lateral mode, and face shear mode sensors, the poling process is much easier than PZT ceramics and PVDF films, due to their low coercive field.

One interesting point is that the low mechanical quality factor of PMN-PT and PZN-PT crystals is not favorable for the sensor application, whereas their wide frequency band characteristic enabled by the low $Q_{\mathrm{M}}$ has been greatly spotlighted for the actuator and transducer applications. This is because that generally wideband sensors usually operate at a frequency range far below their fundamental resonant frequency. Thus, the resonance properties are less relative to the direct piezoelectric sensors. Including this point, a couple of limitations of relaxor-PT single crystal piezoelectric sensors are summarized as follows:

(a) Although the growth method for large crystals have been demonstrated [25], relaxor-PT single crystals still cost more than the lead-based piezo-ceramics;

(b) Relaxor-PT crystals are vulnerable to chipping and cracking during the shaping process of the sensor fabrication due to their low fracture toughness and possibly high internal stresses [121,122];

(c) Low Curie temperature, phase transition temperature, and coercive field of the first generation relaxor single crystals are not favorable for piezoelectric sensors;

(d) High thermal sensitivity of the relaxor crystals requires a proper compensation for the accurate sensing of purposed mechanical stimulus. 
Some of these drawbacks have been partly relieved. First, the problem of the low fracture toughness has been handled by using optimized fabrication processes. Current fabrication of relaxor-PT crystal sensors usually involves the optimal dicing speed, dicing depth, blade type, and lapping speed for the precise sensor shaping without cracks and chips [121,122]. Second, the low temperature limit and the low coercive field of the first generation relaxor crystals have been improved. The second generation crystals, PIN-PMN-PT and PMN-PZT shows increased Curie temperature and phase transition temperature. Compared to PZT-5H ceramics, the thermal operation limit of the second generation crystals is slightly lower but their piezoelectric and dielectric constants are 5 times higher. Third, the second and the third generation crystals exhibit increased coercive field of $5 \mathrm{kV} / \mathrm{cm}$ and about $6 \mathrm{kV} / \mathrm{cm}$, respectively. These values are comparable to PZT-5H $(7 \mathrm{kV} / \mathrm{cm})[61]$. Lastly, the weak thermal stability can be solved with suitable poling direction and crystal phase. [111] poled orthorhombic crystals have the almost temperature-independent piezoelectric constant $d_{33}(850 \mathrm{pC} / \mathrm{N})$ in the range of 20 to $100{ }^{\circ} \mathrm{C}$. Although this is much lower than $d_{33}$ of the conventional [001] poled relaxor crystals but higher than that of PZT ceramics $[25,61]$.

\subsection{Future Perspectives}

To date, the first generation relaxor-PT crystals have been studied for piezoelectric sensor applications due to their ultrahigh piezoelectricity. Compared to other applications such as actuators and transducers, high thermal and field stabilities are considered as more important factors in sensor applications. Thus, the second and the third generation relaxor crystals which have not been actively utilized in the piezoelectric sensors can be promising candidates of the sensing materials of the future sensors in various fields.

\subsubsection{The Second Generation Crystals}

Accelerometers and hydrophones can be made of PIN-PMN-PT and PMN-PZT crystals for the wider operation range of ambient temperature and pressure. Thermal, electrical, and mechanical operation limits can be increased due to their higher transition temperature $\left(\sim 120{ }^{\circ} \mathrm{C}\right)$ and coercive field $(5 \mathrm{kV} / \mathrm{cm})$. Although the piezoelectric and electromechanical coupling constants are about $10 \%$ lower than PMN-PT or PZN-PT, high tunable properties of the second generation crystals can realize the high sensitivity also. For instance, [011] poled 27\%PIN-40\%PMN-33\%PT single crystals have $d_{15}$ of $\sim 500 \mathrm{pC} / \mathrm{N}$, which is much higher than $d_{33}$ of PMN-33\%PT single crystals $(2820 \mathrm{pC} / \mathrm{N})$ [123]. Therefore, this crystal can be used for the thickness-shear-mode accelerometers, normal hydrophones, and vector hydrophones.

\subsubsection{The Third Generation Crystals}

The high mechanical quality factor, together with high piezoelectric coefficients and electromechanical coupling coefficients, indicates that Mn-doped relaxor crystals are promising sensing materials for acoustic load sensors and bio-chemical sensors. The newly designed acoustic load sensors take advantage of the high mechanical quality factor of the face shear mode resonators in comparison with the thickness shear mode relaxor-PT crystal resonators. The fact is that the face shear mode crystal has 
higher figure-of-merit (FOM: $d Q_{\mathrm{M}}$ ) than that of thickness shear mode resonators for the acoustic load sensor application [25]. This FOM is also crucial to the bio-sensor performance, and Mn-doped relaxor crystals have higher FOM than conventional quartz crystals. For example, Mn:PIN-PMN-PT crystals show $d Q_{\mathrm{M}}$ of $910 \mathrm{~nm} / \mathrm{V}$ [25], whereas quartz crystal show about $60 \mathrm{~nm} / \mathrm{V}$. Thus, the third generation relaxor-PT crystals with increased $Q_{\mathrm{M}}$, together with high piezoelectricity, can be promising for tactile and bio-chemical sensors.

\subsubsection{Cryogenic Sensors}

Moreover, many papers regarding cryogenic characteristics and actuator application have been published [124-127]. Based on these results, cryogenic properties of the relaxor-PT single crystals are superior to conventional polycrystalline ceramics [25]. For example, conventional PZT ceramic actuators lost $75 \%$ strain at temperature of $40 \mathrm{~K}$ comparing with room temperature strain. However, relaxor-PT single crystals exhibit significantly higher piezoelectric performance at cryogenic temperatures; $d_{33}$ of the first generation single crystals at $30 \mathrm{~K}$ is about equal to the $d_{33}$ of PZT-5A at room temperature. In addition, the second generation crystals also showed outstanding cryogenic properties [127]. The [001] poled rhombohedral PIN-PMN-PT showed $d_{33}$ of $\sim 1000 \mathrm{pC} / \mathrm{N}$ at $20{ }^{\circ} \mathrm{C}$ and $\sim 800 \mathrm{pC} / \mathrm{N}$ at $-150{ }^{\circ} \mathrm{C}$, whereas polycrystalline soft ceramic showed severe reduction from $\sim 700$ to $\sim 200 \mathrm{pC} / \mathrm{N}$ [128]. Therefore, these outstanding cryogenic performances of relaxor-PT crystals suggest that relaxor-PT crystals can be promising for cryogenic sensing applications.

\section{Author Contributions}

Xiaoning Jiang designed the paper structure and contributed to the manuscript writing and revision. Jinwook Kim collected materials and contributed to the writing on literature survey, relaxor crystals, accelerometers, hydrophones, and bio-chemical sensors. The manuscript of the surface load sensor was prepared by Kyungrim Kim.

\section{Conflicts of Interest}

The authors declare no conflict of interest.

\section{References}

1. Bell, D.; Lu, T.; Fleck, N.; Spearing, S. MEMS actuators and sensors: Observations on their performance and selection for purpose. J. Micromec. Microeng. 2005, 15, doi:10.1088/ 0960-1317/15/7/022.

2. Tabib-Azar, M.; Garcia-Valenzuela, A. Sensing means and sensor shells: A new method of comparative study of piezoelectric, piezoresistive, electrostatic, magnetic, and optical sensors. Sens. Actuators A 1995, 48, 87-100.

3. Kim, K.; Zhang, S.; Huang, W.; Yu, F.; Jiang, X. $\mathrm{YCa} 4 \mathrm{O}_{4}\left(\mathrm{BO}_{3}\right)_{3}$ (YCOB) high temperature vibration sensor. J. Appl. Phys. 2011, 109, 126103:1-126103:3. 
4. Kim, K.; Zhang, S.; Jiang, X. Surface acoustic load sensing using a face-shear PIN-PMN-PT single-crystal resonator. IEEE Trans. Ultrason. Ferroelectr. Freq. Control 2012, 59, doi:10.1109/TUFFC.2012.2488.

5. Wilson, J.S. Sensor Technology Handbook; Newnes: Burlington, MA, USA, 2005.

6. Tadigadapa, S.; Mateti, K. Piezoelectric MEMS sensors: State-of-the-art and perspectives. Meas. Sci. Technol. 2009, 20, 092001:1-092001:30.

7. Drafts, B. Acoustic wave technology sensors. IEEE Trans. Microw. Theory Tech. 2001, 49, 795-802.

8. Vellekoop, M.J. Acoustic wave sensors and their technology. Ultrasonics 1998, 36, 7-14.

9. Nikolelis, D.P.; Varzakas, T.; Erdem, A.; Nikoleli, G. Portable Biosensing of Food Toxicants and Environmental Pollutants; CRC Press: Boca Raton, FL, USA, 2014.

10. Mi, X.; He, F.; Xiang, M.; Lian, Y.; Yi, S. Novel phage-piezoelectric sensor for rapid drug susceptibility testing of Mycobacterium tuberculosis. Sens. Actuators B 2014, 193, 715-722.

11. Li, X.; Zhao, B.; Li, S.; Wu, X.; Ren, W.; Shi, P.; Ye, Z. Resonance Behavior of Piezoelectric Polymer Diaphragms for Biosensors. Ferroelectrics 2014, 459, 38-45.

12. Choi, W.; Lee, J.; Yoo, Y.K.; Kang, S.; Kim, J.; Lee, J.H. Enhanced sensitivity of piezoelectric pressure sensor with microstructured polydimethylsiloxane layer. Appl. Phys. Lett. 2014, 104, 123701:1-123701:4.

13. Yong, Y.K.; Fleming, A.J.; Moheimani, S.R. A novel piezoelectric strain sensor for simultaneous damping and tracking control of a high-speed nanopositioner. Trans. Mechatron. IEEE/ASME 2013, 18, 1113-1121.

14. Tomimatsu, Y.; Takahashi, H.; Kuwana, K.; Kobayashi, T.; Matsumoto, K.; Shimoyama, I.; Itoh, T.; Maeda, R. A piezoelectric flow sensor for use as a wake-up switch for a wireless sensor network node. Mechatronics 2013, 23, 893-897.

15. Schmidtchen, S.; Richter, D.; Fritze, H. Variation of the vibration profile of piezoelectric resonant sensors with different electrode conductivity at high temperatures. Sens. Actuators $B$ 2013, 187, 247-253.

16. Benes, E.; Gröschl, M.; Burger, W.; Schmid, M. Sensors based on piezoelectric resonators. Sens. Actuators A 1995, 48, 1-21.

17. Tressler, J.F.; Alkoy, S.; Newnham, R.E. Piezoelectric sensors and sensor materials. J. Electroceramics 1998, 2, 257-272.

18. Jiang, X.; Kim, K.; Zhang, S.; Johnson, J.; Salazar, G. High-Temperature Piezoelectric Sensing. Sensors 2013, 14, 144-169.

19. Heywang, W.; Lubitz, K.; Wersing, W. Piezoelectricity: Evolution and Future of a Technology; Springer: New York, NY, USA, 2008; Volume 114.

20. Scott, J. Applications of modern ferroelectrics. Science 2007, 315, 954-959.

21. Cross, L.E. Relaxor ferroelectrics. Ferroelectrics 1987, 76, 241-267.

22. Park, S.-E.; Shrout, T.R. Ultrahigh strain and piezoelectric behavior in relaxor based ferroelectric single crystals. J. Appl. Phys. 1997, 82, 1804-1811.

23. Fu, H.; Cohen, R.E. Polarization rotation mechanism for ultrahigh electromechanical response in single-crystal piezoelectrics. Nature 2000, 403, 281-283. 
24. Davis, M. Picturing the elephant: Giant piezoelectric activity and the monoclinic phases of relaxor-ferroelectric single crystals. J. Electroceramics 2007, 19, 25-47.

25. Zhang, S.; Li, F. High performance ferroelectric relaxor- $\mathrm{PbTiO}_{3}$ single crystals: Status and perspective. J. Appl. Phys. 2012, 111, 031301:1-031301:50.

26. Kuwata, J.; Uchino, K.; Nomura, S. Phase transitions in the $\mathrm{Pb}\left(\mathrm{Zn}_{1 / 3} \mathrm{Nb}_{2 / 3}\right) \mathrm{O}_{3}-\mathrm{PbTiO}_{3}$ system. Ferroelectrics 1981, 37, 579-582.

27. Kuwata, J.; Uchino, K.; Nornura, S. Dielectric and piezoelectric properties of $0.91 \mathrm{~Pb}\left(\mathrm{Zn}_{1 / 3} \mathrm{Nb}_{2 / 3}\right) \mathrm{O}_{3}-0.09 \mathrm{PbTiO}_{3}$ single crystals. Jpn. J. Appl. Phys. 1982, 21, 1298-1302.

28. Park, S.-E.; Shrout, T.R. Characteristics of relaxor-based piezoelectric single crystals for ultrasonic transducers. IEEE Trans. Ultrason. Ferroelectr. Freq. Control. 1997, 44, 1140-1147.

29. Zhang, R.; Jiang, B.; Cao, W. Elastic, piezoelectric, and dielectric properties of multidomain $0.67 \mathrm{~Pb}\left(\mathrm{Mg}_{1 / 3} \mathrm{Nb}_{2 / 3}\right) \mathrm{O}_{3}-0.33 \mathrm{PbTiO}_{3}$ single crystals. J. Appl. Phys. 2001, 90, 3471-3475.

30. Ye, Z.-G. Crystal chemistry and domain structure of relaxor piezocrystals. Curr. Opin. Solid State Mater. Sci. 2002, 6, 35-44.

31. Zhang, R.; Jiang, B.; Jiang, W.; Cao, W. Anisotropy in domain engineered $0.92 \mathrm{~Pb}\left(\mathrm{Zn}_{1 / 3} / \mathrm{Nb}_{2 / 3}\right) \mathrm{O}_{3^{-}}$ $0.08 \mathrm{PbTiO}_{3}$ single crystal and analysis of its property fluctuations. IEEE Trans. Ultrason. Ferroelectr. Freq. Control 2002, 49, 1622-1627.

32. Zhang, S.; Laurent, L.; Liu, S.; Rhee, S.; Randall, C.A.; Shrout, T.R. Piezoelectric shear coefficients of $\mathrm{Pb}\left(\mathrm{Zn}_{1 / 3} \mathrm{Nb}_{2 / 3}\right) \mathrm{O}_{3}-\mathrm{PbTiO}_{3}$ single crystals. Jpn. J. Appl. Phys. 2002, 41, doi:10.1143/JJAP.41.L1099.

33. Dammak, H.; Renault, A.-É.; Gaucher, P.; Thi, M.P.; Calvarin, G. Origin of the giant piezoelectric properties in the [001] domain engineered relaxor single crystals. Jpn. J. Appl. Phys. 2003, 42, doi:10.1143/JJAP.42.6477.

34. Zhang, R.; Jiang, B.; Cao, W. Single-domain properties of $0.67 \mathrm{~Pb}\left(\mathrm{Mg}_{1 / 3} \mathrm{Nb}_{2 / 3}\right) \mathrm{O}_{3}-0.33 \mathrm{PbTiO}_{3}$ single crystals under electric field bias. Appl. Phys. Lett. 2003, 82, 787-789.

35. Zhang, S.; Lebrun, L.; Jeong, D.-Y.; Randall, C.A.; Zhang, Q.; Shrout, T.R. Growth and characterization of Fe-doped $\mathrm{Pb}\left(\mathrm{Zn}_{1 / 3} \mathrm{Nb}_{2 / 3}\right) \mathrm{O}_{3}-\mathrm{PbTiO}_{3}$ single crystals. J. Appl. Phys. 2003, 93, 9257-9262.

36. Shanthi, M.; Hoe, K.; Lim, C.; Lim, L. Overpoling-induced property degradation in $\mathrm{Pb}\left(\mathrm{Mg}_{1 / 3} \mathrm{Nb}_{2 / 3}\right) \mathrm{O}_{3}-\mathrm{PbTiO}_{3}$ single crystals of near-morphotropic phase boundary compositions. Appl. Phys. Lett. 2005, 86, 262908:1-262908:3.

37. Shrout, T.R.; Chang, Z.P.; Kim, N.; Markgraf, S. Dielectric behavior of single crystals near the $(1-x) \mathrm{Pb}\left(\mathrm{Mg}_{1 / 3} \mathrm{Nb}_{2 / 3}\right) \mathrm{O}_{3}-(x) \mathrm{PbTiO}_{3}$ morphotropic phase boundary. Ferroelectr. Lett. Sect. 1990, 12, 63-69.

38. Hurle, D.T. Handbook of Crystal Growth; Elsevier: New York, NY, USA, 1994.

39. Moulson, A.J.; Herbert, J.M. Electroceramics: Materials, Properties, Applications, 2nd ed.; John Wiley \& Sons: Chichester, West Sussex, UK, 2003.

40. Lim, L.; Shanthi, M.; Rajan, K.; Lim, C. Flux growth of high-homogeneity PMN-PT single crystals and their property characterization. J. Cryst. Growth 2005, 282, 330-342.

41. Zhang, S.; Li, F.; Luo, J.; Xia, R.; Hackenberger, W.; Shrout, T.R. Investigation of single and multidomain $\mathrm{Pb}\left(\mathrm{In}_{0.5} \mathrm{Nb}_{0.5}\right) \mathrm{O}_{3}-\mathrm{Pb}\left(\mathrm{Mg}_{1 / 3} \mathrm{Nb}_{2 / 3}\right) \mathrm{O}_{3}-\mathrm{PbTiO}_{3}$ crystals with $\mathrm{mm}^{2}$ symmetry. Appl. Phys. Lett. 2010, 97, 132903:1-132903:3. 
42. Cao, H.; Schmidt, V.H.; Zhang, R.; Cao, W.; Luo, H. Elastic, piezoelectric, and dielectric properties of $0.58 \mathrm{~Pb}\left(\mathrm{Mg}_{1 / 3} \mathrm{Nb}_{2 / 3}\right) \mathrm{O}_{3}-0.42 \mathrm{PbTiO}_{3}$ single crystal. J. Appl. Phys. 2004, 96, 549-554.

43. Zhang, Y.; Liu, D.A.; Zhang, Q.; Wang, W.; Ren, B.; Zhao, X.; Luo, H. Complete Set of Material Constants of $<011>$-Poled Rhombohedral Single-Crystal $0.25 \mathrm{~Pb}\left(\mathrm{In}_{1 / 2} \mathrm{Nb}_{1 / 2}\right) \mathrm{O}_{3^{-}}$ $0.47 \mathrm{~Pb}\left(\mathrm{Mg}_{1 / 3} \mathrm{Nb}_{2 / 3}\right) \mathrm{O}_{3}-0.28 \mathrm{PbTiO}_{3}$. J. Electron. Mater. 2011, 40, 92-96.

44. Liu, X.; Zhang, S.; Luo, J.; Shrout, T.R.; Cao, W. A complete set of material properties of single domain $0.26 \mathrm{~Pb}\left(\mathrm{In}_{1 / 2} \mathrm{Nb}_{1 / 2}\right) \mathrm{O}_{3}-0.46 \mathrm{~Pb}\left(\mathrm{Mg}_{1 / 3} \mathrm{Nb}_{2 / 3}\right) \mathrm{O}_{3}-0.28 \mathrm{PbTiO}_{3}$ single crystals. Appl. Phys. Lett. 2010, 96, 012907:1-012907:3.

45. Li, F.; Zhang, S.; Xu, Z.; Wei, X.; Luo, J.; Shrout, T.R. Electromechanical properties of tetragonal $\mathrm{Pb}\left(\mathrm{In}_{1 / 2} \mathrm{Nb}_{1 / 2}\right) \mathrm{O}_{3}-\mathrm{Pb}\left(\mathrm{Mg}_{1 / 3} \mathrm{Nb}_{2 / 3}\right) \mathrm{O}_{3}-\mathrm{PbTiO}_{3}$ ferroelectric crystals. J. Appl. Phys. 2010, 107, 054107:1-054107:5.

46. Zhang, S.; Randall, C.A.; Shrout, T.R. Characterization of perovskite piezoelectric single crystals of 0.43BiScO $3-0.57 \mathrm{PbTiO}_{3}$ with high Curie temperature. J. Appl. Phys. 2004, 95, 4291-4295.

47. Kim, J.; Joh, C.; Roh, Y. Evaluation of All the Material Constants of PMN-28\% PT Piezoelectric Single Crystals for Acoustic Transducers. Sens. Mater. 2013, 25, 539-552.

48. Joh, C.; Kim, J.; Roh, Y. Determination of the complex material constants of PMN-28\% PT piezoelectric single crystals. Smart Mater. Struct. 2013, 22, 125027:1-125027:8.

49. Park, S.-E.; Shrout, T.R. Relaxor based ferroelectric single crystals for electro-mechanical actuators. Mater. Res. Innov. 1997, 1, 20-25.

50. Park, S.-E.E.; Hackenberger, W. High performance single crystal piezoelectrics: Applications and issues. Curr. Opin. Solid State Mater. Sci. 2002, 6, 11-18.

51. Mattiat, O.E.; Belincourt, D.; Kikuchi, Y.; Meitzier, A.H. Ultrasonic Transducer Materials; Plenum Press: New York, NY, USA, 1971.

52. Sherman, C.H.; Butler, J.L. Transducers and Arrays for Underwater Sound; Springer: New York, NY, USA, 2007.

53. Nix, E.; Ward, I. The measurement of the shear piezoelectric coefficients of polyvinylidene fluoride. Ferroelectrics 1986, 67, 137-141.

54. Schewe, H. Piezoelectricity of uniaxially oriented polyvinylidene fluoride. In Proceedings of 1982 Ultrasonics Symposium, San Diego, CA, USA, 27-29 October 1982; pp. 519-524.

55. Kwok, K.W.; Chan, H.L.W.; Choy, C.L. Evaluation of the material parameters of piezoelectric materials by various methods. IEEE Trans. Ultrason. Ferroelectr. Freq. Control 1997, 44, 733-742.

56. Ritter, T.; Geng, X.; Shung, K.K.; Lopath, P.D.; Park, S.-E.; Shrout, T.R. Single crystal PZN/PT-polymer composites for ultrasound transducer applications. IEEE Trans. Ultrason. Ferroelectr. Freq. Control 2000, 47, 792-800.

57. Liu, X.; Zhang, S.; Luo, J.; Shrout, T.R.; Cao, W. Complete set of material constants of $\mathrm{Pb}\left(\mathrm{In}_{1 / 2} \mathrm{Nb}_{1 / 2}\right) \mathrm{O}_{3}-\mathrm{Pb}\left(\mathrm{Mg}_{1 / 3} \mathrm{Nb}_{2 / 3}\right) \mathrm{O}_{3}-\mathrm{PbTiO}_{3}$ single crystal with morphotropic phase boundary composition. J. Appl. Phys. 2009, 106, 074112:1-074112:14.

58. Zhang, S.; Lee, S.-M.; Kim, D.-H.; Lee, H.-Y.; Shrout, T.R. Temperature dependence of the dielectric, piezoelectric, and elastic constants for $\mathrm{Pb}\left(\mathrm{Mg}_{13} \mathrm{Nb}_{23}\right) \mathrm{O}_{3}-\mathrm{PbZrO}_{3}-\mathrm{PbTiO}_{3}$ piezocrystals. J. Appl. Phys. 2007, 102, 114103:1-114103:5. 
59. Zhang, S.; Lee, S.-M.; Kim, D.-H.; Lee, H.-Y.; Shrout, T.R. Characterization of Mn-modified $\mathrm{Pb}\left(\mathrm{Mg}_{1 / 3} \mathrm{Nb}_{2 / 3}\right) \mathrm{O}_{3}-\mathrm{PbZrO}_{3}-\mathrm{PbTiO}_{3}$ single crystals for high power broad bandwidth transducers. Appl. Phys. Lett. 2008, 93, 122908:1-122908:3.

60. Zhang, S.; Shrout, T.R. Relaxor-PT single crystals: Observations and developments. IEEE Trans. Ultrason. Ferroelectr. Freq. Control 2010, 57, 2138-2146.

61. Zhang, S.; Li, F.; Luo, J.; Sahul, R.; Shrout, T.R. Relaxor-PbTiO 3 single crystals for various applications. IEEE Trans. Ultrason. Ferroelectr. Freq. Control 2013, 60, 1572-1580.

62. Zhang, S.; Jiang, X.; Lapsley, M.; Moses, P.; Shrout, T.R. Piezoelectric accelerometers for ultrahigh temperature application. Appl. Phys. Lett. 2010, 96, 013506:1-013506:3.

63. Kim, K.; Zhang, S.; Salazar, G.; Jiang, X. Design, fabrication and characterization of high temperature piezoelectric vibration sensor using YCOB crystals. Sens. Actuators A 2012, 178, 40-48.

64. Wlodkowski, P.; Deng, K.; Kahn, M.; Chase, M. The development of mesoscale accelerometers with single crystal piezoelectric materials. In Proceedings of the 2000 12th IEEE International Symposium on Applications of Ferroelectrics, ISAF 2000, Honolulu, HI, USA, 21 July-2 August 2000; Volume 2, pp. 565-567.

65. Wlodkowski, P.A.; Deng, K.; Kahn, M. The development of high-sensitivity, low-noise accelerometers utilizing single crystal piezoelectric materials. Sens. Actuators A 2001, 90, $125-131$.

66. Seismic/Infrasonic Accelerometer SIA1. Available online: http://www.microfine-piezo.com (accessed on 7 July 2014).

67. McLaughlin, E.A.; Liu, T.; Lynch, C.S. Relaxor ferroelectric PMN-32\% PT crystals under stress, electric field and temperature loading: II-33-mode measurements. Acta Mater. 2005, 53, 4001-4008.

68. McLaughlin, E.A.; Liu, T.; Lynch, C.S. Relaxor ferroelectric PMN-32\% PT crystals under stress and electric field loading: I-32 mode measurements. Acta Mater. 2004, 52, 3849-3857.

69. Liu, T.; Lynch, C. Domain engineered relaxor ferroelectric single crystals. Contin. Mech. Thermodyn. 2006, 18, 119-135.

70. Liu, T.; Lynch, C. Ferroelectric properties of [110], [001] and [111] poled relaxor single crystals: Measurements and modeling. Acta Mater. 2003, 51, 407-416.

71. Guha, J. Effect of compositional modifications on microstructure development and dielectric properties of $\mathrm{Pb}\left(\mathrm{Mg}_{1 / 3} \mathrm{Nb}_{2 / 3}\right) \mathrm{O}_{3}-\mathrm{PbTiO}_{3}$ solid solutions. J. Eur. Ceram. Soc. 2003, 23, 133-139.

72. Goljahi, S.; Gallagher, J.; Zhang, S.; Luo, J.; Sahul, R.; Hackenberger, W.; Lynch, C. A relaxor ferroelectric single crystal cut resulting in large $d_{312}$ and zero $d_{311}$ for a shear mode accelerometer and related applications. Smart Mater. Struct. 2012, 21, 055005:1-055005:6.

73. Wang, L.-P.; Wolf, R.A., Jr.; Wang, Y.; Deng, K.K.; Zou, L.; Davis, R.J.; Trolier-McKinstry, S. Design, fabrication, and measurement of high-sensitivity piezoelectric microelectromechanical systems accelerometers. J. Microelectromechanical Syst. 2003, 12, 433-439.

74. Brown, J.A.; Dunphy, K.; Leadbetter, J.R.; Adamson, R.B.; Beslin, O. Fabrication and performance of a single-crystal lead magnesium niobate-lead titanate cylindrical hydrophone. $J$. Acoust. Soc. Am. 2013, 134, 1031-1038. 
75. He, J.; Liu, Z. Efficient underwater two-dimensional coherent source localization with linear vector-hydrophone array. Signal Process. 2009, 89, 1715-1722.

76. Haun, M.; Newnham, R. An experimental and theoretical study of 1-3 and 1-3-0 piezoelectric PZT-polymer composites for hydrophone applications. Ferroelectrics 1986, 68, 123-139.

77. Smith, W.A. Modeling 1-3 composite piezoelectrics: Hydrostatic response. IEEE Trans. Ultrason. Ferroelectr. Freq. Control 1993, 40, 41-49.

78. Platte, M. A polyvinylidene fluoride needle hydrophone for ultrasonic applications. Ultrasonics 1985, 23, 113-118.

79. Chan, H.; Ramelan, A.H.; Guy, I.; Price, D. Piezoelectric copolymer hydrophones for ultrasonic field characterization. Rev. Sci. Instrum. 1991, 62, 203-207.

80. Lewin, P.A.; Bautista, R.; Devaraju, V. Voltage sensitivity response of ultrasonic hydrophones in the frequency range 0.25-2.5 MHz. Ultrasound Med. Biol. 1999, 25, 1131-1137.

81. Lau, S.; Lam, K.; Chan, H.; Choy, C.; Luo, H.; Yin, Q.; Yin, Z. Ferroelectric lead magnesium niobate-lead titanate single crystals for ultrasonic hydrophone applications. Mater. Sci. Eng. 2004, 111, 25-30.

82. Lau, S.; Lam, K.; Chan, H.; Choy, C.; Luo, H.; Yin, Q.; Yin, Z. Piezoelectric PMN-PT fibre hydrophone for ultrasonic transducer calibration. Appl. Phys. A 2005, 80, 105-110.

83. Yin, Z.-W.; Luo, H.-S.; Wang, P.-C.; Xu, G.-S. Growth, characterization and properties of relaxor ferroelectric PMN-PT single crystals. Ferroelectrics 1999, 229, 207-216.

84. Kim, J.; Roh, Y. Homogenization of PMN-PT/epoxy 1-3 piezocomposites by resonator measurements and finite element analysis. Sens. Actuators A 2014, 206, 97-106.

85. Topolov, V.Y.; Krivoruchko, A.V.; Bowen, C.R.; Panich, A.A. Hydrostatic Piezoelectric Coefficients of the 2-2 Composite Based on [011]-poled $0.71 \mathrm{~Pb}\left(\mathrm{Mg}_{1 / 3} \mathrm{Nb}_{2 / 3}\right) \mathrm{O}_{3}-0.29 \mathrm{PbTiO}_{3}$ Single Crystal. Ferroelectrics 2010, 400, 410-416.

86. Dogan, A.; Fernandez, J.; Uchino, K.; Newnham, R.E. The “cymbal” electromechanical actuator. In Proceedings of the 1996 Tenth IEEE International Symposium on Applications of Ferroelectrics, ISAF'96, East Brunswick, NJ, USA, 18-21 August 1996; Volume 1, pp. 213-216.

87. Fernandez, J.; Dogan, A.; Zhang, Q.; Tressler, J.; Newnham, R. Hollow piezoelectric composites. Sens. Actuators A 1996, 51, 183-192.

88. Tressler, J.F.; Cao, W.; Uchino, K.; Newnham, R.E. Finite element analysis of the cymbal-type flextensional transducer. IEEE Trans. Ultrason. Ferroelectr. Freq. Control 1998, 45, 1363-1369.

89. Li, Z.; Huang, A.; Luan, G.; Zhang, J. Finite element analyzing of underwater receiving sensitivity of PMN-0.33 PT single crystal cymbal hydrophone. Ultrasonics 2006, 44, e759-e762.

90. Uzgur, E.; Markley, D.C.; Guo, M.; Snyder, B.; Meyer, R.; Dogan, A.; Newnham, R.E. Pressure dependence of cymbal transducers. IEEE J. Ocean. Eng. 2007, 32, 408-415.

91. Gao, J.; Xu, Z.; Li, F.; Zhang, C.; Liu, Y.; Liu, G.; He, H. The hydrostatic piezoelectricity of relaxor- $\mathrm{PbTiO}_{3}$ ferroelectric ceramics and crystals. J. Adv. Dielectr. 2012, 2, 1250018:1-1250018:5.

92. Cray, B.A. Acoustic Vector Sensor. U.S. Patent 6,370,084 B1, 9 April 2002.

93. Shipps, J.C.; Deng, K. A miniature vector sensor for line array applications. In Proceedings of OCEANS 2003, San Diego, CA, USA, 22-26 September 2003. 
94. Shipps, J.C.; Abraham, B. The use of vector sensors for underwater port and waterway security. In Proceedings of the ISA/IEEE Sensors for Industry Conference, New Orleans, LA, USA, 27-29 January 2004; pp. 41-44.

95. Deng, K.K. Underwater acoustic vector sensor using transverse-response free, shear mode, PMN-PT Crystal. J. Acoust. Soc. Am. 2006, 120, 3439-3439.

96. Todorova, V.; Kolev, D. Design and modeling problems of resonance piezoelectric tactile arrays. In Proceedings of the 2009 IEEE Control Applications, (CCA) \& Intelligent Control, (ISIC), St Petersburg, Russia, 8-10 July 2009; pp. 1433-1436.

97. Jalkanen, V.; Andersson, B.; Lindahl, O. Stiffness of a small tissue phantom measured by a tactile resonance sensor. In Proceedings of the XII Mediterranean Conference on Medical and Biological Engineering and Computing 2010, Chalkidiki, Greece, 27-30 May 2010; pp. 395-398.

98. Hemsel, T.; Stroop, R.; Oliva Uribe, D.; Wallaschek, J. Resonant vibrating sensors for tactile tissue differentiation. J. Sound Vib. 2007, 308, 441-446.

99. Oie, T.; Suzuki, H.; Murayama, Y.; Fukuda, T.; Omata, S.; Kanda, K.; Takamizawa, K.; Nakayama, Y. Surface elasticity imaging of vascular tissues in a liquid environment by a scanning haptic microscope. J. Artif. Organs 2010, 13, 121-125.

100. Schmitt, R.; Scott, W.; Irving, R.; Arnold, J.; Bardons, C.; Halpert, D.; Parker, L. Ultrasonic imaging of fingerprints using acoustical impediography. In Proceedings of the 2004 IEEE Ultrasonics Symposium, 23-27 August 2004; Volume 1, pp. 680-688.

101. Schmitt, R.M.; Owen, J. Acoustic impediography: Imaging surface acoustic impedance using 1-3 piezo-composite for integrated fingerprinting. In Proceedings of the 2011 IEEE 61st Electronic Components and Technology Conference (ECTC), Lake Buena Vista, FL, USA, 31 May-3 June 2011; pp. 1296-1299.

102. Kim, K.; Zhang, S.; Jiang, X. Surface load induced electrical impedance shift in relaxor-PbTiO crystal piezoelectric resonators. Appl. Phys. Lett. 2012, 100, 253501:1-253501:4.

103. Zhang, S.; Li, F.; Jiang, W.; Luo, J.; Meyer, R.J.; Cao, W.; Shrout, T.R. Face shear piezoelectric properties of relaxor- $\mathrm{PbTiO}_{3}$ single crystals. Appl. Phys. Lett. 2011, 98, 182903:1-182903:3.

104. Zhang, S.; Jiang, W.; Meyer, R.J., Jr.; Li, F.; Luo, J.; Cao, W. Measurements of face shear properties in relaxor-PbTiO 3 single crystals. J. Appl. Phys. 2011, 110, 064106:1-064106:6.

105. Kim, K.; Zhang, S.; Tian, J.; Han, P.; Jiang, X. Face-shear mode ultrasonic tactile sensor array. In Proceedings of the 2012 IEEE International Ultrasonics Symposium (IUS), Dresden, Germany, 7-10 October 2012; pp. 1059-1062.

106. Sapsford, K.E.; Bradburne, C.; Delehanty, J.B.; Medintz, I.L. Sensors for detecting biological agents. Mater. Today 2008, 11, 38-49.

107. Machado, R.F.; Laskowski, D.; Deffenderfer, O.; Burch, T.; Zheng, S.; Mazzone, P.J.; Mekhail, T.; Jennings, C.; Stoller, J.K.; Pyle, J. Detection of lung cancer by sensor array analyses of exhaled breath. Am. J. Respir. Crit. Care Med. 2005, 171, 1286-1291.

108. Ebersole, R.C.; Ward, M.D. Amplified mass immunosorbent assay with a quartz crystal microbalance. J. Am. Chem. Soc. 1988, 110, 8623-8628.

109. Ebersole, R.C.; Foss, R.P.; Ward, M.D. Piezoelectric cell growth sensor. Nat. Biotechnol. 1991, 9, 450-454. 
110. Wang, J.; Ward, M.D.; Ebersole, R.C.; Foss, R.P. Piezoelectric pH sensors: AT-cut quartz resonators with amphoteric polymer films. Anal. Chem. 1993, 65, 2553-2562.

111. Voinova, M.; Jonson, M.; Kasemo, B. Missing mass effect in biosensor's QCM applications. Biosens. Bioelectron. 2002, 17, 835-841.

112. Lederer, T.; Stehrer, B.P.; Bauer, S.; Jakoby, B.; Hilber, W. Utilizing a high fundamental frequency quartz crystal resonator as a biosensor in a digital microfluidic platform. Sens. Actuators $A$ 2011, 172, 161-168.

113. Bunde, R.L.; Jarvi, E.J.; Rosentreter, J.J. Piezoelectric quartz crystal biosensors. Talanta 1998, 46, 1223-1236.

114. Yang, K.; Li, Z.; Chen, D. Design and Fabrication of a Novel T-Shaped Piezoelectric ZnO Cantilever Sensor. Act. Passiv. Electron. Compon. 2012, 2012, 834961:1-834961:7.

115. Xiao, Y.; Liu, Y.; Borg, G.; Withers, R.L.; Li, Z.; Xu, Z.; Li, C.M. Lead magnesium niobate-lead titanate piezoelectric immunosensors. Sens. Actuators A 2010, 163, 82-87.

116. Ward, M.D.; Buttry, D.A. In situ interfacial mass detection with piezoelectric transducers. Science 1990, 249, 1000-1007.

117. Hong, Y.K.; Park, H.-K.; Lee, S.Q.; Moon, K.S.; Levy, M. Fabrication of a piezoelectric biosensor based on a PZN-PT/PMN-PT single crystal thin film. In Proceeding of SPIE International Conference on Optomechatronic Sensors Actuators and Control, Philadelphia, PA, USA, 25-26 October 2004; Volume 5602, pp. 140-147.

118. Moon, K.S.; Hong, Y.K. PMN-PT single crystal resonators for ultra-sensitive vapor sensing. Optomech. Technol. 2005, 2005, 60480C:1-60480C:7.

119. McGovern, J.-P.; Shih, W.Y.; Shih, W.-H. In situ detection of Bacillus anthracis spores using fully submersible, self-exciting, self-sensing PMN-PT/Sn piezoelectric microcantilevers. Analyst 2007, 132, 777-783.

120. Frank, M.; Moon, K.S.; Kassegne, S. A PMMA coated PMN-PT single crystal resonator for sensing chemical agents. Smart Mater. Struct. 2010, 19, 035015:1-035015:12.

121. Jiang, X.; Snook, K.; Hackenberger, W.S.; Geng, X. Single crystal piezoelectric composites for advanced NDT ultrasound. In Proceedings of the 14th International Symposium on: Smart Structures and Materials \& Nondestructive Evaluation and Health Monitoring, San Diego, CA, USA, 18 March 2007; Volume 6531, pp. 65310F:1-65310F:18.

122. Jiang, X.; Snook, K.; Walker, T.; Portune, A.; Haber, R.; Geng, X.; Welter, J.; Hackenberger, W.S. Single crystal piezoelectric composite transducers for ultrasound NDE applications. In Proceedings of the 15th International Symposium on: Smart Structures and Materials \& Nondestructive Evaluation and Health Monitoring, San Diego, CA, USA, 9 March 2008; Volume 6934, pp. 69340D:1-69340D:10.

123. Zhang, S.; Liu, G.; Jiang, W.; Luo, J.; Cao, W.; Shrout, T.R. Characterization of single domain $\mathrm{Pb}\left(\mathrm{In}_{0.5} \mathrm{Nb}_{0.5}\right) \mathrm{O}_{3}-\mathrm{Pb}\left(\mathrm{Mg}_{1 / 3} \mathrm{Nb}_{2 / 3}\right) \mathrm{O}_{3}-\mathrm{PbTiO}_{3}$ crystals with monoclinic phase. J. Appl. Phys. 2011, 110, 064108:1-064108:4.

124. Hackenberger, W.; Luo, J.; Jiang, X.; Snook, K.; Rehrig, P.; Zhang, S.; Shrout, T. Recent developments and applications of piezoelectric crystals. In Handbook of Advanced Dielectric, Piezoelectric and Ferroelectric Materials-Synthesis, Characterization and Applications; Ye, Z.G., Ed.; Woodhead: Cambridge, England, UK, 2008; pp. 73-100. 
125. Jiang, X.; Rehrig, P.W.; Hackenberger, W.S.; Smith, E.; Dong, S.; Viehland, D.; Moore, J., Jr.; Patrick, B. Advanced piezoelectric single crystal based actuators. In Proceeding of Smart Structures and Materials 2005: Active Materials: Behavior and Mechanics, San Diego, CA, USA, 6 March 2005; Volume 5761, pp. 253-262.

126. Jiang, X.; Rehrig, P.W.; Luo, J.; Hackenberger, W.S.; Zhang, S.; Shrout, T.R. Low-voltage single crystal actuators. In Proceeding of Smart Structures and Materials 2006: Active Materials: Behavior and Mechanics, San Diego, CA, USA, 26 February 2006; Volume 6170, pp. 61700G:1-61700G:8.

127. Jiang, X.; Cook, W.B.; Hackenberger, W.S. Cryogenic piezoelectric actuators. In Proceeding of Astronomical and Space Optical Systems, San Diego, CA, USA, 2 August 2009; Volume 7439, pp. 74390Z:1-74390Z:8.

128. Li, F.; Zhang, S.; Xu, Z.; Wei, X.; Luo, J.; Shrout, T.R. Piezoelectric activity of relaxor-PbTiO 3 based single crystals and polycrystalline ceramics at cryogenic temperatures: Intrinsic and extrinsic contributions. Appl. Phys. Lett. 2010, 96, 192903:1-192903:3.

(C) 2014 by the authors; licensee MDPI, Basel, Switzerland. This article is an open access article distributed under the terms and conditions of the Creative Commons Attribution license (http://creativecommons.org/licenses/by/3.0/). 